\title{
DECISŌES METODOLÓGICAS DE APRENDIZAGEM MOTORA: ANÁLISE E REFLEXŌES DA METODOLOGIA DA DIDÁTICA DO ESPORTE
}

Gerhard Hecker*

\section{RESUMO}

O autor estuda as publicações dos últimos 25 anos referentes ao comportamento e ação metodológica na aula de educação física seguida de orientaçōes e decisōes para

UNITERMOS: Aprendizagem motora. Didática do Esporte.

\section{INTRODUÇĀO}

Nos útlimos 25 anos 3 publicações ligadas ao tema citado obtiveram especial atençāo e tiveram grande influência na formação de professores de educação física. atuação de professores de educação física em programa de aprendizagem de Movimento.
(*) Nota do tradutor (Kurmaier, P.G.):

Devido às opiniōes divergentes e ainda indefinidas no que diz respeito à terminologia de educação física, esporte, "educação corporal", faz-se necessário um esclarecimento nesse sentido. Acompanhando o processo da educação física, temos hoje uma situação, èspecificamente no caso da Alemanha, no qual o termo "Sport" (Esporte) é o termo mais abrangente, englobando todas as áreas afins. Assim, sendo que esse texto baseia-se nos padrões alemães alerta-se para que quando se leia o termo Esporte, consiga-se perceber o seu alcance, e não eventualmente associá-lo unicamente a esporte competitivo, por exemplo. Dentro desse contexto pode-se entender melhor o porque de "Esporte para Todos", aplicado à áreas que são técnicas, adaptadas, recreativas, competitivas, etc...., todas subentendidas no termo Esporte. 
do Ensino na educação física

Seguiram-se ainda mais 4 volumes complementares desse tema.

Fetz inicia seu 1을 capítulo com uma citação de Pestalozzi: "Eu Ihes digo, que a simples formação do Espírito, separada, alheia ao desenvolvimento das forças físicas e morais dos seres humanos, é um engano" Aqui poder-se-ia acrescentar à indicação de Pestalozzi, que a Natureza nos dá a criança como um todo inseparável.

Stiehler parte da condição prévia que na escola não se necessita de nenhum dualismo da educação mental e física e tampouco da educação moral, formal. Ele prossegue: $(1973,21)$ - " A educação político-ideológica, moral, mental, física, politécnica e estética não se realiza através de uma matéria de aula, e sim no processo global da formação e educação socialista"

Do ponto de vista da teoria pedagógica isso é óbvio. No entanto, esses pontos nem sempre determinam a atividade de aula dos professores especializados e ainda não são suficientes para o conteúdo da metodologia especializada. E Koch/Mielke $(1968,10)$ colocam: No entanto, no campo de atividades de esporte, jogo, ginástica, nas quais os motivos básicos de nossa cultivada forma de movimentação se apresenta fora do contexto de uma atividade motivante e prática, (Bernett) abrem-se fontes de experiência e vivência e com isso possibilidades objetivas que são indispensáveis para os jovens, na sua auto-compreensão e conhecimento do mundo. $E$ mais tarde, voltando-se para o aluno: que condições psicológicas, antropológicas são dadas, das quais cresce a inclinação para um assunto e para a espontaneidade? De que forma o aluno como atuante é motivado pelo que é oferecido? ( $\mathrm{H}$. Roth) pois a intensidade do esforço para alcançar um objetivo de comportamento só será suficientemente forte, se a individualidade do aluno, seu grau de amadurecimento psíquico, físico, senso-motor e sua situação individual (Pestalozzi) forem incluídos nas reflexōes metodológicas. Assim, ao lado da precisão vem a adequaçāo em relação ao subjetivo como o momento estrutural dominante do ensino na educaçāo física. Portanto, percebe-se que os 4 autores não vêm a aprendizagem motora isoladamente. Muitas vezes eles indicam as importantes ligaçōes com a área psíquica e social, e Stiehler menciona pontos de vista abrangendo matérias e especializações.

Não se objetiva aqui questionar se os leitores da referida literatura incorporaram essas indicações gerais e as incluiram na sua rotina de aula, ou se freqüentemente agiram acreditando que nas suas aulas diárias năo tivesse mais sentido concentrar-se numa técnica motora específica. Também não se pretende testar se os 4 autores se tornaram fiéis conseqüentes das suas próprias reivindicaçōes. Principalmente em ligação com a discussão curricular e a conseqüente estimulaçảo para o aprimoramento, a precisảo nos objetivos de ensino e que em muitas escolas, o pensamento concentrado em objetivos mais selecionados determina o que acontece na aula. Um desses objetivos selecionados poderia determinar: as crianças devem conseguir realizar o movimento para o arremesso. Porém, uma noção de objetivo como essa só pode ser válida, se estiver associada a um fator de formulação operacionalizada dos objetivos de aprendizagem. Entretanto, muitos autores alertam que essa formulação pode levar à perda de valiosas perspectivas de objetivo.

Porém, para reflexões metodológicas e delas determinar medidas metodológicas a perspectiva de objetivos é de grande significado. Vice-versa, também as reflexōes metodológicas e as decisões podem ter efeitos adversos sobre a formulação do objetivo. Nos útlimos anos foi alertado sob diversos ângulos sobre essa relaçāo. Ao mesmo tempo não se fala nem da interdependência nem da implicação dessa relação. pontos:

$\mathrm{Na}$ introduçăo deve-se orientar para 2

1. Tanto nas decisões de conteúdo como nas decisóes metodológicas deve-se sempre ser pensado que "a natureza nos dá a criança como um todo inseparável" Por isso, a concentração exclusiva num único aspecto nảo pode ser admitida.

2. Objetivo, conteúdo e decisões metodológicas estão relacionados, e essa relação é caracterizada por uma implicação de dependência. Assim, é levantada a questão, que também nas reflexōes metodológicas e decisōes tomadas surge o compromisso do empenho para a identificação das interligaçōes existentes. 


\section{A METODOLOGIA É UM TEMA MENOS- PREZADO DA PEDAGOGIA DO ESPORTE?}

Para que não ocorram mal-entendidos, algumas observaçōes em relação à terminologia se fazem necessários. A metodologia é entendida como uma parte da didática e a didática como parte da pedagogia. Ao mesmo tempo, a didática é utilizada para processos de ensino e aprendizagem, e a metodologia ocupa-se da questão como os objetivos podem ser alcançados e por que determinados métodos são utilizados. Sendo que nos processos de ensino e aprendizagem podem surgir objetivos concorrentes, em muitos casos os respectivos métodos escolhidos são responsáveis pela acentuação de um determinado objetivo. Os conceitos de aprender e ensinar são prioritários ao conceito de aula, pois assim um campo maior é abordado e também, situações de aprendizagem são incluídas, pelas quais o professor é responsável, nas quais ele também permanece num $2^{\circ}$ plano. No livro recentemente apresentado "Para a determinação da situação atual da pedagogia do esporte" ciue Peper e Christmann publicaram em homenagem ao pedagogo de esporte J.N. Schmitz, Brodtmann representou a opinião de que os métodos de aula são um tema menosprezado na pedagogia do esporte. Durante a leitura do artigo, constata-se que ele dirige sua opinião para um sentido muito específico. Em última instância, ele pretende uma verificação: em que implica a relação entre objetivos, conteúdos e métodos, e de que isso não é sempre bem considerado. O principal ponto da questão é se as decisões metodológicas atuam mais no sentido de sistematizar ou de superar a sistematização. Brodtmann claramente manifesta que para ele métodos de aula têm uma importância tal que através da sua influência sistemas existentes podem ser superados. Porém, uma decisão como essa só pode ter sentido, se antes se tenha claro na decisão como essa só pode ter sentido, se antes se tenha claro na decisão de objetivos que o sistema deva ser questionado e superado. Se isso não for - objetivo (superar o sistema), a decisão metodológica seria diferente.

Todos aqueles que se colocarem a favor, de que formas de esporte tradicionais no sentido de que sejam praticadas pelas regras e valores internacionais, certamente encontrarão decisōes metodológicas diferentes daqueles que alcançarem modificações nas formas de esporte sem orientação para a competição. Decisōes de objetivos e decisōes metodológicas estão portanto todo o tempo relacionadas e podem influenciar-se mutuamente, na sua lógica relação estão ordenados de uma maneira tal, que a decisão de objetivos pode servir como uma justificativa, mas jamais uma decisão metodológica pode ser uma justificativa, para a decisão de objetivos.

A mencionada primazia da didática vale tanto antes como depois para a relação entre objetivos e métodos. Ele vale no entanto igualmente para a relação entre objetivos e conteúdos. Isso não significa que decisōes de objetivos sejam mais importantes ou mais valiosos que decisões metodológicas. Reflexões metodológicas podem levar a novas idéias de objetivos, as decisōes de objetivos devem entretanto ser aceitas como independentes dessas reflexōes metodológicas. É verdade que podemos chegar ao resultado, à conclusão de que determinados objetivos só podem ser alcançados através de determinados métodos, e que isso constitui uma ligação obrigatória entre as duas decisões. Porém, essa afirmação não é suficiente para a decisão de objetivos. Uma segunda preocupação que se percebe em Brodtmann, é dirigida à conclusão de que em muitos casos, as orientaçōes metodológicas não são aplicadas de forma justa ao aluno. Isso certamente ocorre quando através do método são indicados formas de aprendizagem extremamente fixas, e que assim a individualidade dos alunos não recebe a devida atenção, nesse ponto não há como negar essa afirmaçāo. Aliás, no que diz respeito a esse tema, todo professor está diante de uma difícil tarefa. Isso vale mais ainda, quando um professor tem muitos alunos a acompanhar. Aqui, a facilidade maior é a do treinador de alto nível que é responsável somente por poucos atletas. Ao contrário, estāo o professor numa escola, o orientador esportivo nos clubes e também o fisioterapeuta na reabilitação com a exigência da inidividualizaçāo.

Pelo exemplo de programas de aprendizagem o problema pode ser esclarecido. Programas de aprendizagem deixam diferenças individuais a respeito do tempo de 
aprendizagem, porém em programas lineares pensa-se em todos os alunos que recebem a mesma forma de aprendizagem. $O$ problema foi recebido e por isso esforçou-se para realizar programas ramificados, nos quais sejam possíveis diferentes formas de aprendizagem. Porém para a área de Apren-

dizagem no Esporte esses resultados apresentados ainda não são satisfatórios na maioria dos casos. Com muita certeza, o campo geral da Aprendizagem Esportiva também não pode estar confiado aos programas de aprendizagem. Justamente no ponto de vista da individualização, o professor pode concretamente adequar-se e entrar em sintonia com o aluno.

\section{ALGUMAS ORIENTAÇŌES REFERENTES À LITERATURA EM QUESTĀO}

No ramo desse assunto em questão não se pode oferecer um panorama geral da literatura. O sentido desse texto é indicar algumas tendências. A já formulada pergunta, se metodologia é um tema menosprezado na literatura, pode-se referente à quantidade responder negativamente. Existe uma gama de publicações que apresentam todas as implicações metodológicas. Planos de ensino fornecidos por Ministérios ou por associações especializadas contêm indicações minuciosas de medidas metodológicas, para serem observados nos respectivos processos de aprendizagem. Em muitas revistas especializadas são continuamente dadas orientações no sentido metodológico para professores de educação física, e finalmente também existe uma série de teorias que podem ser exploradas. Assim, a cibernética "apadrinhou" um modelo didático, ao qual são dirigidas questões metodológicas. Em geral, a teoria de informação e a questão, quais informaçōes e de que forma são trabalhadas pelos alunos, são importantes bases para decisōes metodológicas. Teorias de socialização permitem indicações, que são importantes exatamente para processos sociais de aprendizagem.

Especialmente o elemento-jogo foi influenciado por teorias de socialização. (Dietrich/Landau 1976, 1977 a.b.). Nessa interligação, também a dinâmica de grupo deve ser mencionada, que especialmente para o acompanhamento de grupos de lazer tem fornecido importantes conhecimentos bási- cos. Aqui vale mencionar os já conhecidos experimentos de Sherif. O conceito de pesquisa de pequenos grupos foi especialmente apresentado em relação à Educação Física. A teoria da motivação trouxe consigo significativa influência sobre a discussão da metodologia. Isso ocorre, porque processos de aprendizagem sempre são bastante influenciados por direcionamentos de motivação que correm paralelamente. Aqui, os resultados mais importantes são as recomendações para a diferenciação, a recomendação para a valorização de tempos de práticas mais longos e mais independente para alunos e a relação entre motivação extrínseca e intrínseca. (Hecker, 1982).

A psicologia não deu somente sugestões, e estímulos relacionados a trabalhos de aprendizagem teórica para processos de aprendizagem no esporte. Sempre estão presentes questōes metodológicas, se tratando tanto de aprendizagem de treinamento autógeno ou como da possibilidade de "biofeedback", que podem encontrar valiosas consideraçōes no processo de aprendizagem, ou também se são trabalhos orientados para a psicologia da Gestalt, que já foram relacionados mais vezes com processos de aprendizagem no esporte. (Sonnenchein, 1985; Kohl, 1956, 1977; Tholey, 1980; Gallwey, 1982; Nitsch e outros, 1979; Tschakert e outros, 1981).

Naturalmente a medicina do esporte e a biomecânica podem ter um papel de apoio nas decisões metodológicas (Comparativamente ao estudo de Wiemann nesse volume).

O dilema no qual nos encontramos não é a falta mais sim a enorme gama de auxílios possiveis para decisões metodológicas. Sintomática para essa situação é o novo livro de Rieder e Fisher "Metodologia e didática no esporte", que diz respeito a lazer, educação física escolar, esporte de rendimento, grupos especiais e onde eles apresentam um grande número de sugestões, porém também lamentam por ter sido impossivel para eles, considerarem a totalidade do que é oferecido. Assim, encontramos no livro um rico índice literário e uma grande gama de valiosas informaçōes, estimulantes referências e indicações. Porém, certamente a sistemática estrutura do livro não encontrará ressonância positiva em todos os contextos, e em toda parte. Nós nos encontramos portanto peran- 
te a tarefa, de ter que reduzir de forma sensata, quando quisermos dar ao professor sugestōes praticáveis. Certamente, hoje os trabalhos dos 4 autores mencionados (Fetz, Stiehler e Kock/Mielke) no início são valiosos, se os professores conseguirem lidar com eles de forma crítica. Com isso, é chamada a atenção para o aspecto que a capacidade do professor de educação física, que no artigo de Brodtmann é julgada muito mais como céptica, no entanto, aparece finalmente como a decisiva posição para decisões metodológicas concretas nos casos individuais.

Nós não necessitamos de esforços especiais para a realização de novos exercícios ou séries de jogos; a respeito da relação professor/aluno muito já foi afirmado; planejamento de aula e estrutura de carga horária já foram tratados por muitos autores; existem muitas orientações sobre a postura verbal e a postura do professor de realizar à frente do aluno. Porém, sempre se afirma de forma vaga e não coordenada ou resumida sobre a totalidade do que já existe. O que agora é necessário, é o desenvolvimento da capacidade dos professores de educação física, de ver as interligações e conseguir trabalhá-las. Juntamente com isso, ele deve, relacionado à sua situação concreta de aprendizagem, conseguir uma redução sensata das informaçōes. Na formação de professor e na organização de aperfeiçoamento deve-se cuidar portanto para que o professor possa desenvolver a capacidade de, simultaneamente a um conhecimento dos fatos e um considerável panorama literário, realizar essa redução mencionada. Isso pode ser demonstrado apenas em exemplos concretos de aula. Nesse trabalho de redução não se deve chegar a decisōes definitivas e inequivocadas, e sim deve existir abertura para medidas complementares quando os processos de aprendizagem nāo ocorrem da maneira planejada.

Por isso, vias de formação de professores nos quais não se dê espaço suficiente para a prática de aula nāo podem ser satisfatórios. A indicação literária contida nesse artigo aconteceu muito mais por um acaso. $O$ objetivo era de mostrar que existe uma gama de literatura orientada pedagogicamente que indica implicaçōes metodológicas.

\section{PODEM FÓRMULAS NĀO PRONTAS SE- REM ÚTEIS PARA OS PROFESSORES ATUANTES?}

A referida pergunta surge a partir das reflexōes anteriores. Sendo que não parece sensato, oferecer ao professor processos de aprendizagem que ele aplique ao pé da letra, as sugestões deveriam sempre apresentar uma parte de abertura para condiçōes específicas de uma situação.

Assim sendo, fala-se aqui de fórmulas não prontas. As indicaçōes que são dadas têm um caráter generalizado e necessitam de uma complementação de acordo com cada processo concreto de aprendizagem acompanhado pelo professor. As seguintes recomendações possuem um caráter subjetivo já que se baseiam nos conhecimentos e experiências do autor.

- o professor deve sempre entender que é um auxiliar do aluno. Ele deve auxiliar, para que o aluno possa aprender. Ao mesmo tempo, não deve jamais deixar de acreditar que o aluno tem a capacidade de aprender; isso exige dele bastante flexibilidade. Sempre quando o professor percebe que o aluno tem dificuldades insuperáveis num determinado objetivo, ele deve conseguir modificar a perspectiva do objetivo; seja qual for entāo o objetivo que se tenha em vista, cabe ao professor, em muitos casos em acordo com o aluno, decidir na situação. O professor é portanto um auxiliar para o aluno, no entanto aprender cabe a cada um. O aprender não é realizado pelo professor.

- de essencial significância é a arte de saber dosar corretamente. Isso não vale somente na área físico-energética. Também a carga social, psíquica pode ser demasiado alta, demasiado baixa ou adequada. Assim, o professor deve ter sensibilidade para perceber o grau de medo de um aluno, assim como identificar as dificuldades no convívio social. Atenção especial deverá ser dada à dosagem das informaçōes dadas ao aluno. Devem ser sempre dadas tantas informaōes, quantas possam ser trabalhadas pelo aluno. Isso ganha mais significado, quando é visto em ligação com as correçōes que são exteriorizadas pelo professor ao aluno.

- em relação à linguagem é importante que o professor cuide para que o alunom realmente compreenda sua lingua- 
gem. Ex: numa aula de ski, é dada a orientação de realizar o movimento a partir dos joelhos. No mesmo momento, ele poderá orientar sobre partes do corpo e sua relação. Essa mesma expressão foi utilizada de formas diferentes por professores diferentes no mesmo aluno. Isso não seria negativo se o aluno entender e souber distinguir as interpretações da expressão.

- de grande significação metodológica é dupla face do "explorar" do aluno, descrita por Klafki. Por um lado, o professor deve cuidar para que se ofereça ao aluno situações opostas de aprendizagem, para serem exploradas, e ao mesmo tempo auxiliar o aluno a se abrir para essas situações opostas.

- todos os aspectos mencionados estão relacionados à exigência da diferenciaçăo, principalmente referente à diferenciaçăo interna do aluno. O professor encontra-se perante difícil tarefa; ele deve respeitar o poder do desempenho e a inclinação, tendência de cada aluno, deve considerar as diferenças características de personalidade - por exemplo, mais ou menos medo - e a maneira mais satisfatória para que a informaçāo seja aproveitada. Possibilidades de diferenciação acontecem mais quando o professor coloca uma tarefa, na qual surgem situaçőes que exigem decisões dos alunos, e onde simultaneamente as crianças se tornam ativas individualmente, e é quando o professor pode dar auxílio adequado $e$ individualizado. Naturalmente a diferenciação também é possível através da divisão em grupos.

- em relação à diferenciação, existe uma outra recomendação: os alunos devem sempre ter a oportunidade de poder se esforçar de forma perseverante e repetitiva em um processo de aprendizagem. Maria Montessori trouxe orientação a respeito de capacidades especiais em crianças. Através dessa forma de ensino, as crianças chegam à capacidade de se autofortalecerem, caminhando para a motivação intrínseca.

- nessa relação também pode ser utilizada a forma de tentativa e erro, porém somente quando os alunos forem capazes de julgar seus resultados, portanto quando eles conseguem comprovar o certo/errado de suas experiências.

- de forma semelhante também recomenda-se que tanto quanto for possível, sejam dadas oportunidades para aprendizagens globais. Por exemplo, uma série de exercícios com pouco auxílio têm muito mais um caráter global, do que quando existe uma divisão, classificaçāo em unidades funcionais.

- progressos no movimento sempre são problemáticos, pois nunca são perfeitos no detalhe em proporção à evolução do movimento; isso vale especialmente para a forma mais fina do movimento, por exemplo, em atletas que dominam a tarefa, o professor pode supor que a percepção cinestésica do atleta seja melhor do que a capacidade de observação do treinador. Diálogos oferecem melhores auxílios aos alunos quando são baseados mais em perguntas ao aluno do que instruçð̋es do professor. Por exemplo, o professor pergunta ao aluno: "Você fez um erro? Qual? No que você deverá estar atento nas próximas tentativas?"

- sempre deve haver abertura nas decisỏes metodológicas para particularidades dos alunos.

- o medo do aguçamento de erros nos movimentos muitas vezes é exagerado. Muitos erros desaparecem por si com a prática. Porém, isso nāo quer dizer que não exista o perigo do aguçamento de erros.

- como professor, não se deve imaginar que os processos de aprendizagem ocorrem detalhadamente como o planejamento. O professor deve sempre estar preparado para influências inesperadas ou sugestōes. Muitas vezes elas podem representar auxílio no processo de aprendizagem, ou também obstáculos negativos.

- do professor é exigido que possa pensar relaçōes e interligações complexas e ser capaz de oferecer seus auxílios no sentido dessas interligaçōes indentificadas. Separar aspectos de uma parte é muito mais uma exceção no processo de aprendizagem. Isso vale também para o planejamento 
de aula, assim, por exemplo, não é satisfatório no nível primário querer praticar o movimento de levantar o braço no arremesso separadamente: também esse exemplo vem da observação na aula de educação física.

- todo professor deveria saber que alunos são sujeitos de aprendizagem, que têm sua maneira própria.

- portanto é exigido do professor aceitação e empatia pelos alunos; ele precisa aceitar o aluno como ele é, e pode refletir sobre medidas, de como o seu comportamento pode ser modificado. O professor deve saber compartilhar com o aluno, deve entender o sentimento de medo, por exemplo.

- quando os alunos reconhecem no professor que ele é conseqüente e tem simpatia por eles, resulta uma boa atmosfera de aprendizagem, que influencia positivamente o trabalho conjunto entre professor e aluno.

- a maioria das sugestōes aqui apresentadas é dirigida ao indivíduo. Muitas delas orientam para as relaçōes com o comportamento social e podem ser transferidas para processos de aprendizagem sociais. A idéia de que temos de decidir, por um lado entre apoio de prontidão de aprendizagem e por outro a aprendizagem social, desencontra-se com a maioria das oportunidades de aprendizagem, se levarmos em conta as recomendaçōes aqui dadas. Quase sempre resulta a possibilidade que sejam criadas oportunidades de aprendizagem, nas quais complexas idéias de objetivo acompanham processos de aprendizagem.

\section{OBSERVAÇÕES FINAIS}

Após a retrospectiva do desenvolvimento e da situação da literatura metodológica dos últimos 25 anos, que no contexto desse artigo só pode ser apresentada resumidamente e com exemplo escolhidos, foram formuladas recomendaçōes para os professores de educaçāo física atuantes, com respeito à escolha de decisōes metodológicas. É desenvolvida a idéia que "fórmulas não prontas" podem ser um auxílio valioso na busca de decisões metodológicas convenientes, se o professor de educação física possuir a capacidade, seguindo o sentido dessas sugestōes, de encontrar valiosas decisōes complementares à situação dos processos de aprendizagem planejados e acompanhados por ele. As "fórmulas não prontas" serão então entendidas como fórmulas de aprendizagem, nas quais ainda pode ser encontrado o "desconhecido, o incógnito"

\section{Zusammenfassung}

Der Autor zeigt die Veröffentlichungen der letzten 25 Jahren über die Zusammenhang zwischen motorisches Lernen und methodische Entscheidungen. Die vorgegebene Thema ist von besondere Beachtung wegen der grossem Einfluss auf die Ausbildungsgänge von Sportlehrern.

\section{REFERÊNCIAS BIBLIOGRÁFICAS}

1. Auswahl Vier. Aus den Schwalbacher Blättern. Bd. 1, Gruppenpädagosgiche Grundlagen. Wiesbaden, 1978.

2. Brodtmann, D. Unterrichtsmethoden das vernachlässigte Thema der Sportpädagogik. In: Peper, D./Christimann, E. (Hrsg): Zur standortbestimmung der Sportpädagogik. Schornodorf, 1987 68-83.

3. Dietrich, K./Landau, G. (Hrsg) Beiträge zur Didaktik der Sportspiele. Teil I: Spiel in der Leibeserziehung. Schorndorf, 1976.

4. Dietrich, K./Landau, G. (Hrsg) Beiträge zur Didaktik der Sportspiele. Teil II: Analysen, Interpretationen, Folgerungen. Schorndorf, 1977

5. Dietrich, K./Landau, G. (Hrsg) Beiträge zur Didaktik der Sportspiele. Teil III: Sportspiel im Unterricht. Schorndorf, 1977

6. Fetz, F Aligemeine Methodik der Leibesünbugen. Wien, 1961, Frankfurt/M., 1975.

7. Gallwey, T. Tennis und Psyche. Das innere Spiel München, 1982. 
8. Gallwey, T./Kriegel, B. Besser Skifahren durch Inner-Training. München, 1978.

9. Grossing, St. (Hrsg) Spektrum der Sportdidaktik. Handbücher zur Pädagogik und Didaktik des Sports. Bd. 2. Bad Homburg v. d. H., 1979.

10. Hahn, E./Rieder, H. (Hrsg) Sensumotorisches lernen und Sportspielforschung. (Festschrift zum 65. Geburtstag von Prof. Dr. Kurt Kohl). Köln, 1984.

11. Hecker, G. Aufgabenkanon für $\mathbf{1 0 0}$ Sportstnden im 1. und 2. Schuljanr. Schorndorf, 1982.

12. Hecker, G./Küpper, D. Trendbericht Sportdidaktik. In: Sportunterricht (Sonderheft: Trendberichte aus der Sportwissenschaft) 1984, 36-47

13. Klein, M. Zur Problematik der Kleingruppenforschung. Köln, 1980.

14. Knappe, W/Hasenkrüger, $H$. (Leiter des Autorenkollektivs) Methodik des Sportunterrichts. Bd. 1 u. 2. Potsdam, 1980.

15. Koch, K./Meyners, E. Unterichtsplanung. Unterrchtsbeobachtung. Uterrichtsbeurteilung. Die Gestaltung des Unterrichts in der Leibeserziehung. Teil V Schorndorf, 1977.

16. Koch, K./Mielke, W. Die Gestaltung des Unterrichts in der Leibeserziehung. Tell I. Schorndorf, 1968, 1977.

17. Koch, K./Söll, W. Stundenmodelle für alle Altersstufen. Die gestaltung des Unterrichts in der Leibeserziehung. Tel III. Schorndorf, 1984.

18. Kohl, K. Zum problem der Sensumotorik. Frankfurt, 1956.

19. Kohl, K. Gestalttheorie bei der behandlung des motorischen Lernens im Gebiet des Sports. In: Guss, K. (Hrsg): Gestalttheorie und Fachdidaktik. Darmstadt, 1977, 64-83.

20. Kohl, K. Psychologische Erkenntnis und Sportpraxis. Ahrensburg, 1979.
21. Lenk, $H$. Leistungsmotivation und Mannschaftsdynamik. Schorndorf, 1970.

22. Nitsch, J. R./Allmer, H./Sonnenschein, I./Tradt, A./Tschakert, R. Untersuchungen zu naiven Techniken der Psychoregulation im Sport. Teil I: Selbstregulation. Köln, 1979.

23. Rieder, H./Fischer, G. Methodik und Didaktik im Sport. München, 1986.

24. Sherif, M. A Study of Some Social Factors in Perception. In: Hofstätter, P R.: Gruppendynamik. Reinbek, 1957

25. Söll, W. Differenzierung im Sportunterricht.Teil I. Die Gestaltung des Unterrichts in der Leibeserziehung. Teil IV. Schorndorf, 1976.

26. Söll, W.Koch, K. Übungsmodelle für alle Altersstufen. Die Gestaltung des Unterrichts in der Leibeserziehung. Teil II. Schorndorf, 1976.

27. Sonnenschein, I. Das Kölner Psychoregulationstraining. Ein Handbuch für Trainingsleiter. Köln, 1985.

28. Stiehler, G. (Red) Methodik des Sportunterrichts. Berlin-Ost, 1966, 1973.

29. Tholey, P. Erkenntnistheoretische und systemtheoretische Grundlagen der Sensumotorik aus gestalttheoretischer Sicht. In: Sportwinssenschaft 10 (1980), H. 1, 7-35.

30. Tschakert, R./Hackfort, D./Sonneschein, I./Tradt, A./Nitsch, J. R. Untersuchungen zu naiven Techniken der Psychoregulation im Sport. Teil II: Fremdregulation. Köln, 1981.

31. Veit, H. Untersuchungen zur Gruppendynamik von Ballspielmannschaften. Schorndorf, 1971.

* Prof. Dr. Phil., Chefe do Instituto für Didaktik des Schulsports da Deutsche Sporthochschule Köln - R.F.A

TRADUÇĀO: Priscila Gabriela Kurmeier REVISĀO: Alberto Carlos Amadio 